\title{
Pancreatic polypeptide
}

\author{
T. E. ADRIAN
}

From the Department of Medicine, Royal Postgraduate Medical School, Du Cane Road, London W12 0HS

Pancreatic polypeptide (PP) was discovered fortuitously during the purification of insulin from birds (Kimmel et al., 1968) and later from mammals (Chance et al., 1976). PP has since been extracted and purified from several mammalian species. It contains 36 amino-acid residues and is quite distinct from other known hormonal peptides (Lin and Chance, 1974). The amino-acid sequence of the peptides extracted from man, pig, dog, sheep, and cow differs only in one or two residues in positions 2 , 6 , or 23 (Lin and Chance, 1974). The biological activity of these mammalian peptides has been found to reside in the $\mathrm{C}$ terminal hexapeptide (Lin and Chance, 1978). Rodent PP, however, appears to be somewhat different in that it does not cross-react with the majority of antisera raised to the bovine peptide.

\section{Localisation}

PP is localised almost entirely to the pancreas where it is produced by discrete, small, granular endocrine cells (Fig. 1) which are scattered throughout the exocrine parenchyma as well as being found in the periphery of the islets (Adrian et al., 1976; Heitz et al., 1976; Larsson et al., 1976). The PP cells display the ultrastructural features of the $D_{1}$-cell of the revised Wiesbaden classification (Solcia et al., 1973). It has been suggested that the cell producing PP should now be given the functional label of the PP cell (Solcia et al., 1978).

\section{Release of PP}

PP circulates in plasma and levels rise rapidly after the ingestion of food, particularly protein and fat, and remain raised for several hours (Fig. 2) (Hazelwood et al., 1973; Floyd et al., 1976; Polak et al., 1976; Schwartz et al., 1976). This rise is abolished by total pancreatectomy indicating that the pancreas is the only significant source of this peptide in the circulation (Adrian et al., 1977b). Intravenous infusions of amino-acids, glucose, or lipids do not significantly alter circulating PP levels, so that an entero-PP axis must exist. A substantial increase in plasma PP concentration is also observed during

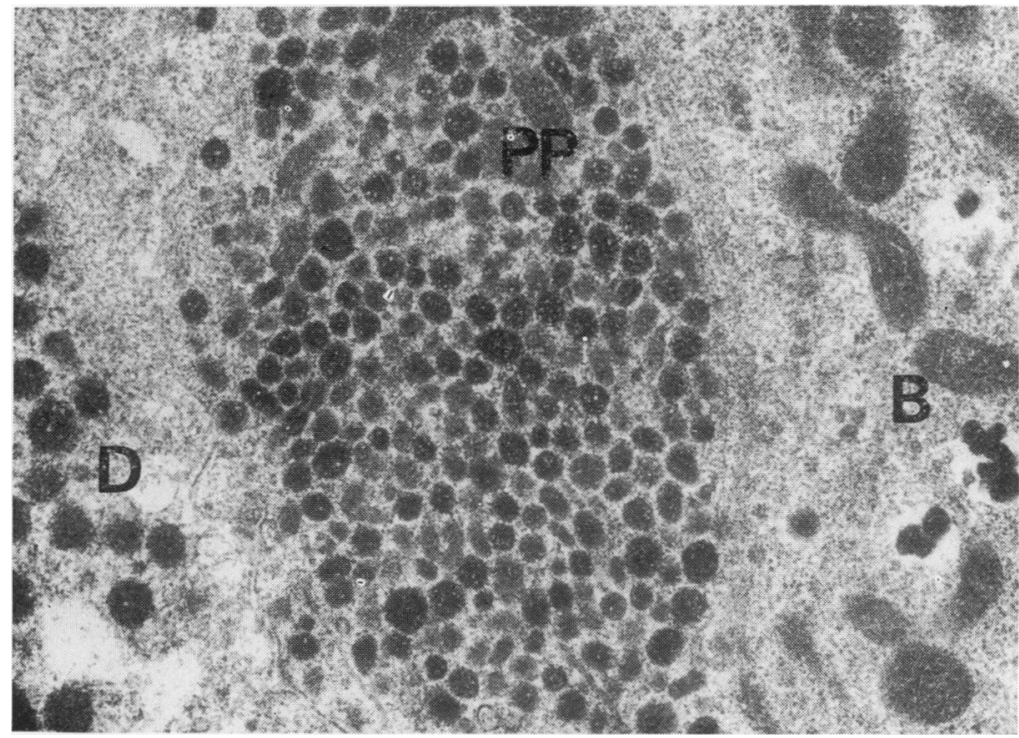

Fig. 1 Electron micrograph showing a PP cell in an islet of Langerhans and also showing $a$ $B$-cell $(B)$ and a somatostatin cell (D). (Original magnification $\times 30$ 000). 
insulin-induced hypoglycaemia, the peak coinciding with the lowest blood glucose concentrations (Floyd et al., 1976; Adrian et al., 1977b; Schwartz et al., 1978). This effect is, however, blocked by truncal vagotomy, indicating that it is mediated through stimulation of the vagus (Adrian et al., 1977b). Immediately after therapeutic vagotomy the PP response to food is impaired (Schwartz et al., 1976), but several months after vagotomy it is normal (Adrian et al., 1977b; Taylor et al., 1978a). Thus, vagal stimulation is not the only mechanism of PP release. In the isolated perfused canine pancreas caerulein, a cholecystokinin analogue, glucosedependent insulin-releasing polypeptide (GIP), vasoactive intestinal peptide (VIP), and gastrin, all caused a significant increase in perfusate $\mathrm{PP}$ concentration (Adrian et al., 1978b). Acetyl choline also caused a

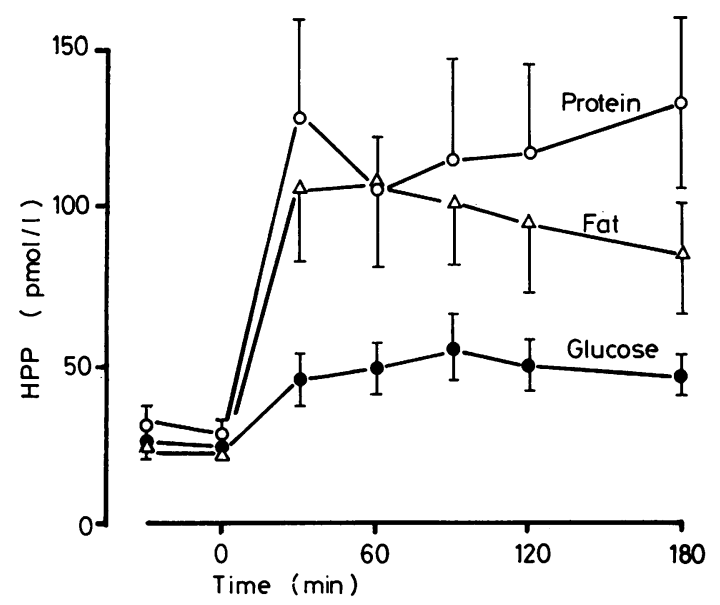

Fig. 2 Effect of individual meal components on plasma PP (HPP) levels in 6 healthy subjects. very marked release in this preparation and may을 enhance the release evoked by other substances.

Gastrointestinal hormones are potent stimulators $\frac{-}{0}$ of PP release in man (Adrian et al., 1977b). Secretin $\frac{C}{0}$ alone has no effect on PP levels (Adrian et al.,1979b) but an infusion of cholecystokinin and secretin $\overrightarrow{\mathbb{D}}$ combined increased the plasma PP concentration from $21 \pm 5 \mathrm{pmol} / 1$ to $94 \pm 11 \mathrm{pmol} / 1$ (Fig. 3). Very ${ }^{\infty}$ low doses of caerulein $(123 \mathrm{fmol} / \mathrm{kg} / \mathrm{min})$ combined $\vec{\circ}$ with a very low dose of secretin $(137 \mathrm{fmol} / \mathrm{kg} / \mathrm{min}) \overrightarrow{\vec{H}}$ caused an increase in plasma PP of $117 \pm 26 \% \omega$ $(\mathrm{P}<0.005)$ within 90 minutes.

The entero-PP axis, therefore, appears to have two components, the vagus and gastrointestinal hor- $\vec{p}$ mones. A complex interrelationship between these $\stackrel{-}{-}$ two components is suggested by the effect of atropine which, in normal subjects, blocks the PP response to gut hormones and also lowers fasting levels of $\mathrm{PP}$ (Adrian et al., 1978a). Some degree of cholinergic $c_{\vec{c}}$ tone seems to be essential both for maintaining basal secretion of PP and for the response to gut hormones. This may be considered to be analogous to the release of acid from the gastric parietal cell which is $\overrightarrow{0}$ dependent on the interaction of acetyl choline, $\infty$ gastrin, and histamine; the removal of any one of these very greatly diminishes acid production aftecaia meal.

Gastric distension, either by water (Adrian et al., 1978a) or a balloon (Schwartz et al., 1979), evokesळ a significant release of $\mathrm{PP}$ in man, perhaps through $\mathrm{a} \stackrel{2}{\overrightarrow{7}}$ local reflex. A local reflex may also be responsible in $\frac{0}{3}$ part for the PP response to hypoglycaemia as, in addition to being abolished by truncal vagotomy, this is also reduced by selective vagotomy (Adrian et al., 1978a). Gastric acid secretion does not seem to? be important in the postprandial release of PPO which is not affected by the administration of cimetidine (Taylor et al., 1978a), and only slightly soô

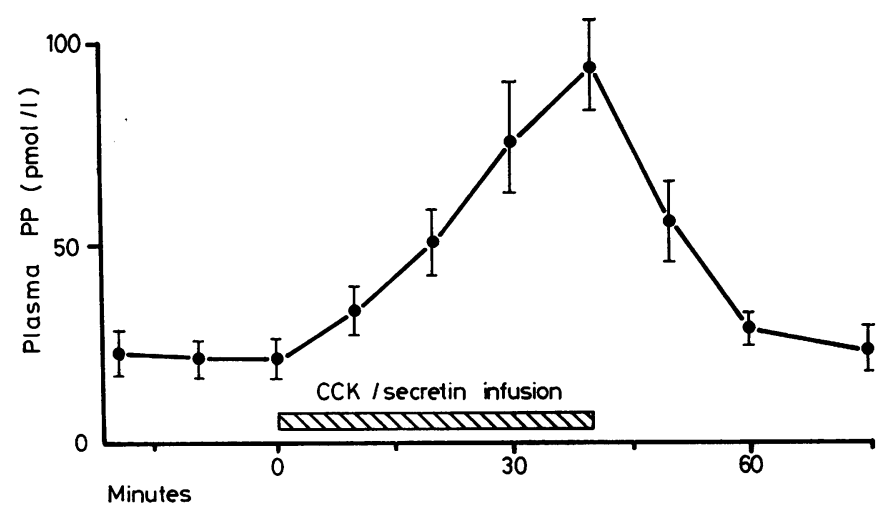

Fig. 3 Effect of an infusion of cholecystokinin (approx $10 \%$ pure CCK 0.5 IDU/kg/h) and secretin (pure natural secretin $137 \mathrm{fmol} / \mathrm{kg} / \mathrm{min}$ ) on plasma $P P$ concentrations in 4 healthy subjects. 
by the instillation of hydrochloric acid into the duodenum (Floyd et al., 1976).

In common with insulin, glucagon, and all of the gastrointestinal hormones so far investigated, the release of PP both in the basal and postprandial state is inhibited by somatostatin (Adrian et al., 1977a; Floyd et al., 1977; Marco et al., 1977).

\section{Actions of PP}

Following the isolation and purification of bovine PP, Lin and Chance carried out a systematic study of the biological actions of the peptide on the canine gastrointestinal tract (Lin and Chance, 1974, 1978; Lin et al., 1977). The effects of PP included stimulation of gastric acid secretion, but inhibition of that stimulated by pentagastrin. PP inhibited the secretion of pancreatic juice, and particularly of pancreatic enzymes, both in the basal state and when stimulated by an infusion of cholecystokinin and secretin. The gall bladder was relaxed and the tone of the choledochal sphincter was increased. Gastric emptying and intestinal transit were enhanced in the rat.

\section{Infusion of $P P$ in man}

A vital step in establishing that a possible hormone does have a physiological role is to show that a biological response occurs when infusion of the substance produces a circulating concentration similar to that seen after natural stimuli. Therefore, in order to elucidate whether any of the actions of PP mentioned above could be considered to be physiological in man, bovine PP was infused at several doses from 1 to $5 \mathrm{pmol} / \mathrm{kg} / \mathrm{min}$ in a total of 48 healthy subjects. Plasma levels rose to above those seen postprandially and reached a plateau by 30 minutes. The mean half life was 6.9 minutes (SEM $\pm 0.3 ; n=23)$, the metabolic clearance rate was $5 \cdot 1 \pm 0 \cdot 2 \mathrm{ml} / \mathrm{kg} / \mathrm{min}$, and the apparent space of distribution was $51 \pm 3 \mathrm{ml} / \mathrm{kg}$, which approximates to the plasma volume (Adrian et al., 1978c). The short half life of PP indicates that the sustained rise after eating is the result of active release for several hours after eating.

In the basal state the infused PP significantly reduced the volume of pancreatic juice and the output of trypsin (for both, $\mathrm{P}<0 \cdot 02$ ), and also abolished the output of bilirubin into the small intestine (Greenberg et al., 1979). When PP was infused during a low dose infusion of pure secretin, 200 $\mathrm{fmol} / \mathrm{kg} / \mathrm{min}$, bicarbonate output was reduced by $25 \pm 8 \%$, which reflected the change in the volume of duodenal juice $(P<0.05)$, and pancreatic enzyme secretion as measured by duodenal juice protein and tryptic activity was reduced by $67 \pm 7 \%$ and $59 \pm$
$6 \%$, respectively $(\mathrm{P}<0 \cdot 001)$ (Adrian et al., 1979b) (Fig. 4, 5). The bilirubin output also fell significantly during these experiments $(P<0 \cdot 01)$. When doses of PP which mimicked the postprandial rise were superimposed on an infusion of small doses of secretin (137 $\mathrm{fmol} / \mathrm{kg} / \mathrm{min})$ and caerulein (123 $\mathrm{fmol} / \mathrm{kg} / \mathrm{min})$ there was a $60 \%$ reduction of trypsin output and an $80 \%$ reduction of bilirubin output (for both, $\mathrm{P}<0.001$ ) (Greenberg et al., 1978b). In cholecystectomised patients, trypsin output was reduced by this procedure to the same degree as in normal subjects but bilirubin output was unaffected, suggesting that PP had two quite separate effects in man, inhibition of pancreatic enzyme secretion and relaxation of the gall bladder.

Gastric acid and pepsin secretion were unaffected by infusion of PP, both in the basal state and during submaximal stimulation of acid secretion by pentagastrin (Peptavlon $15 \mathrm{pmol} / \mathrm{kg} / \mathrm{min}$; Greenberg et al., 1978a). Its effect on gastric emptying was studied in five healthy subjects by infusing PP or saline during the ingestion of a small carbohydraterich solid breakfast chosen because it elicited only a small release of endogenous PP. The half-emptying time when PP was infused $(66 \pm 7 \mathrm{~min})$ was not significantly different from that when saline was infused $(71 \pm 11 \mathrm{~min})$. In addition, the emptying rate during a higher PP dose, giving levels similar to those seen after a large mixed lunch, was not significantly changed $(60 \pm 12 \mathrm{~min})$. All infusions

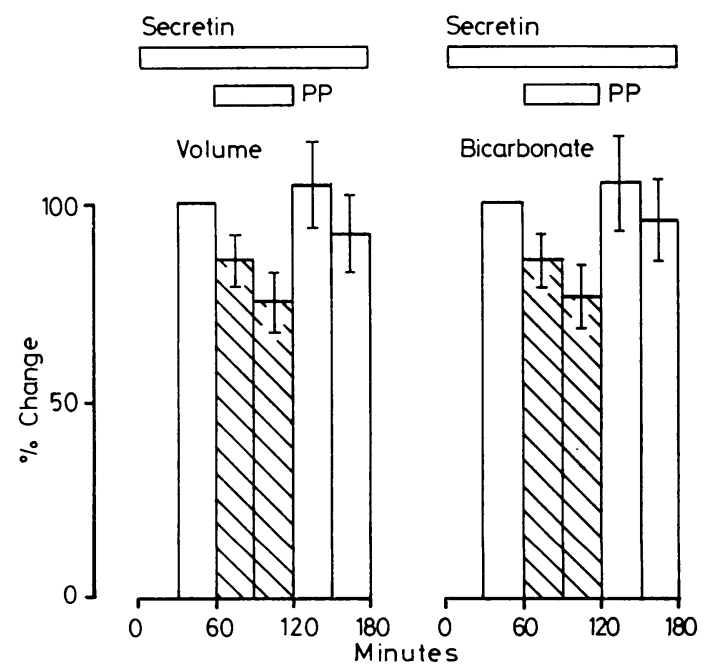

Fig. 4 The effect of bovine PP (3.3 pmol $/ \mathrm{kg} / \mathrm{min})$ on duodenal juice volume and bicarbonate output in 5 healthy subjects during stimulation with secretin (pure secretin $200 \mathrm{fmol} / \mathrm{kg} / \mathrm{min}$ ). Values represent $\%$ of output during the 30 minute period before PP infusion. 


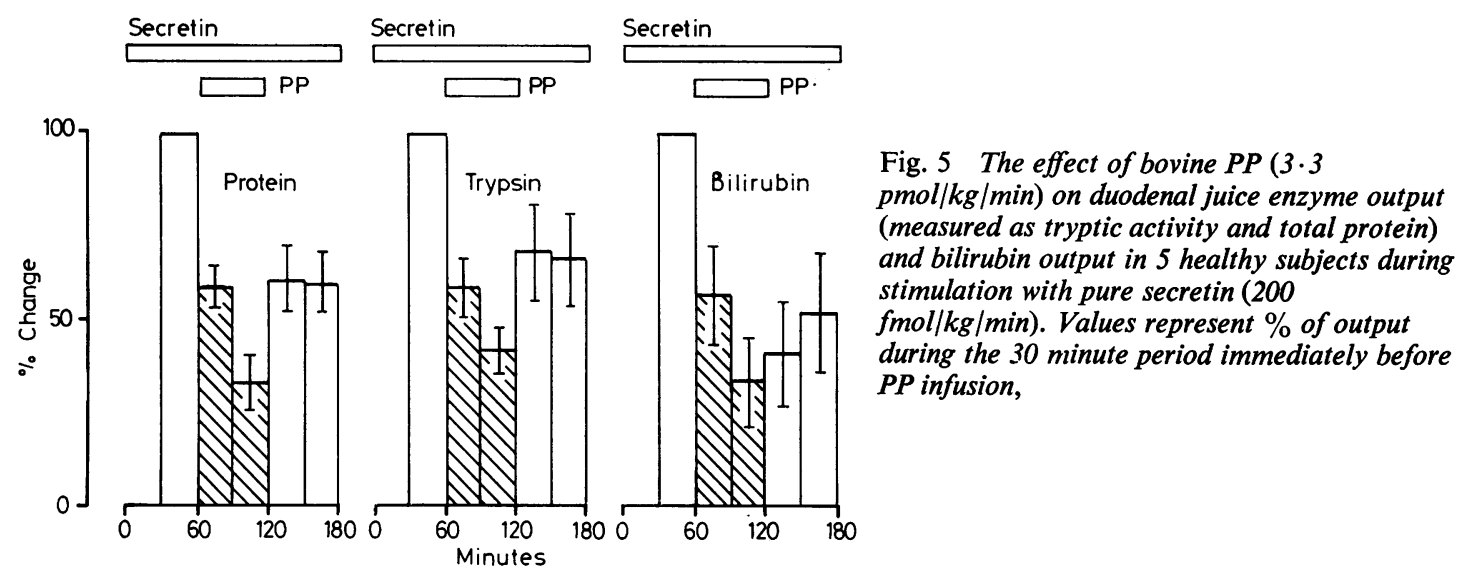

in this study were given blind and in random order (Adrian et al., 1979c). Basal and postprandial responses of the hormones insulin, glucagon, gastrin, secretin, enteroglucagon, and glucose-dependent insulin-releasing polypeptide (GIP) were not significantly altered by the infusions. In contrast there was an $80 \%$ reduction in fasting concentrations of motilin, a peptide which stimulates gastrointestinal motor activity $(\mathrm{P}<0.001)$ (Adrian et al., 1978d). No change in circulating concentrations of glucose or its intermediary metabolites was observed during PP infusion (Adrian et al., 1978e). Thus, PP is unlikely to be a physiological modulator of carbohydrate metabolism, gastric secretion, or gastric emptying rate in man. However, these studies do suggest that PP may have a role in the physiological regulation of gall bladder function and of pancreatic enzyme secretion in man. Similar observations have been reported in the dog (Taylor et al., 1978b).

\section{Pathophysiology of PP}

\section{EFFECT OF AGE}

The fasting plasma PP concentration increases with age in normal subjects (Floyd et al., 1977; Taylor et al., 1978c). The postprandial rise is also greater in older healthy subjects than in young controls (Fig. 6). It is therefore of great importance when comparing groups of patients with normal subjects that the two groups are matched for age.

\section{DIABETES}

Raised plasma PP levels have been reported in both maturity onset and juvenile type diabetes, but the overlap between diabetics and normal subjects is considerable (Floyd et al., 1977). Hyperplasia of PP cells in the pancreatic islets of juvenile diabetics has also been reported (Orci et al., 1976). In a group of

young, well controlled patients on monocomponent $\overrightarrow{\lrcorner}$ insulin we have found PP levels to be identical with those of normal subjects. Because PP is present as a contaminant in most of the available commercial insulin preparations, though not monocomponent insulins, some $60 \%$ of conventionally insulin treated diabetics studied have circulating antibodie which bind to PP. High affinity antibodies are particularly frequent in young insulin-dependent diabetics where both the duration of therapy and the insulin dosage are related to the development of antibodies (Bloom et al., 1979).

It is to be hoped that this induced autoimmunity

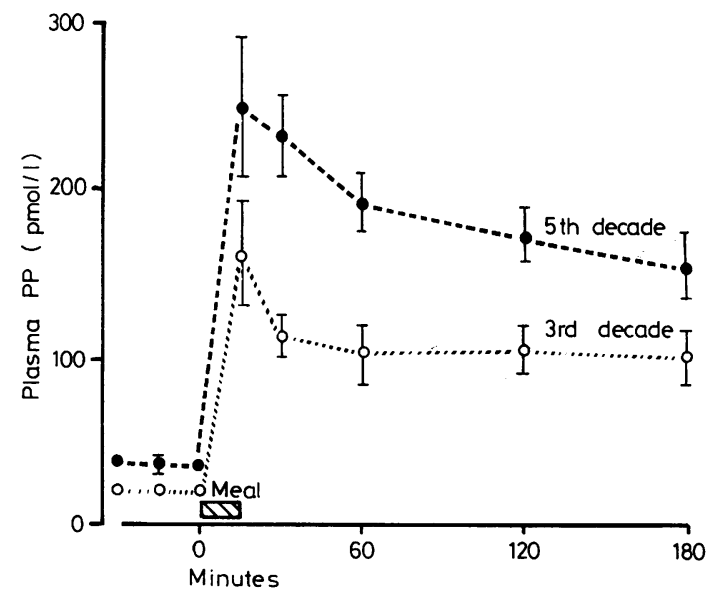

Fig. 6 Plasma PP concentrations after the ingestion of a standard test breakfast in fasting normal volunteers in their 3rd decade $(n=9)$ and 5th decade $(n=7)$. The postprandial response is significantly different at $30 \mathrm{~min}(P<0.001), 60 \mathrm{~min}(P<0.005)$, $120 \min (P<0.02)$, and $180 \min (P<0.05)$. 
will be avoided in the future by the use of highly purified insulins.

\section{OBESITY}

The obese hyperglycaemic mouse (ob/ob) is the most intensively studied animal model of human late onset diabetes mellitus. Parabiotic animal experiments where ob/ob animals maintain normal weight when paired with normal but not ob/ob mates have led to the conclusion that the hyperphagia and resulting weight gain is the result of the lack of circulating satiety factor from the gut which in normal animals controls food intake (Coleman, 1978). It has been reported that the administration of PP reverses the hyperphagia and weight gain in these mice, which subsequently become normoglycaemic (Malaisse-Lagae et al., 1977). Studies on the release of PP in the obese mouse are awaited with interest. We have shown (unpublished observations) that the pancreas of the fat mouse contains a normal amount of extractable PP-like immunoreactivity $(147 \pm 14 \mathrm{pmol} / \mathrm{g})$ compared with that of the lean litter mate $(124 \pm 10 \mathrm{pmol} / \mathrm{g})$. However, a reduction in the number of $\mathrm{PP}$ cells has previously been reported (Orci et al., 1976).

In man, PP release by a standard test breakfast in 19 patients with morbid obesity $(225 \pm 7 \%$ ideal weight) was not significantly different from that seen in 16 healthy age- and sex-matched normal controls $(106 \pm 3 \%$ ideal weight). In addition the PP response was unaffected by ileojejunal bypass in the obese patients (Besterman et al., 1978c).

\section{PEPTIC ULCER}

Because of the observed actions of bovine PP on acid secretion in the dog it was of particular interest to investigate PP release in patients with duodenal ulcer. Both fasting concentrations of PP $(n=40)$ and the response to food $(n=21)$ in duodenal ulcer patients were similar to those seen in age-matched cớntrols (Adrian et al., 1977b). It seems unlikely, therefore, that PP is involved in the pathogenesis of this syndrome.

\section{STEATORRHOEA}

As PP release appears to be controlled by mechanisms similar to those which control the secretion of pancreatic enzymes, it was clearly of interest to investigate its release in patients with chronic pancreatitis. The PP response to food is grossly impaired in patients with chronic pancreatitis and steatorrhoea (Adrian et al., 1977a; Adrian et al., 1979a); there was a similarly impaired response to the intravenous injection of secretin ${ }^{1}$ which normally stimulates PP release. In patients with chronic pancreatitis without 1 A comparatively impure preparation obtained from Boots. overt exocrine deficiency the release of PP was not significantly different from normal. In contrast to the findings in pancreatic steatorrhoea, patients with steatorrhoea resulting from active coeliac disease or acute tropical sprue had normal basal and peak levels of PP after the meal. The measurement of PP may thus provide confirmatory evidence that steatorrhoea is of pancreatic origin, but it is unhelpful in assessing chronic pancreatitis without exocrine deficiency, where there is a diagnostic problem.

\section{DIARR HOEA}

The infusion of low doses of PP in the dog caused a marked increase in the motility of the gastric antrum, duodenum, ileum, and colon ( $\mathrm{Lin}$ and Chance, 1978), and the substance was patented as a potential veterinary laxative. We therefore investigated the postprandial PP response in patients with diarrhoea resulting from several different causes. Plasma PP levels after our standard test breakfast were not significantly raised in 12 patients with acute infective diarrhoea, in 14 patients with Crohn's disease, and in 24 patients with ulcerative colitis (Besterman et al., 1978b). Patients with the irritable bowel syndrome had a moderately increased release of PP after the test breakfast. However, this increased response was noted in patients who presented with constipation as well as those with diarrhoea.

\section{GUT RESECTION}

PP release appears to be potentiated by an intestinal factor. Its source was investigated by studying plasma PP release after our standard test breakfast in 18 patients with partial ileal resection and nine patients with partial colonic resection for inflammatory bowel disease, neoplasia, radiation, fibrosis, or trauma; the operations had been performed at least one year before the study.

Both basal and postprandial PP levels were surprisingly raised in these two groups of patients (Besterman et al., 1978a). Further work is required to elucidate the cause and effect of this.

\section{PANCREATIC ENDOCRINE TUMOURS}

Over half of the endocrine tumours of the pancreas and their metastases so far investigated contain large numbers of PP cells which can be shown by immunofluorescence (Polak et al., 1976). Hepatic and lymph node metastases sometimes contain even higher concentrations of immunoreactive PP than the primary pancreatic tumour, indicating that PP is a product of the tumour. Plasma levels are often grossly raised in these patients, sometimes exceeding 1000 times the normal basal level. The measurement of plasma PP may thus provide additional evidence 


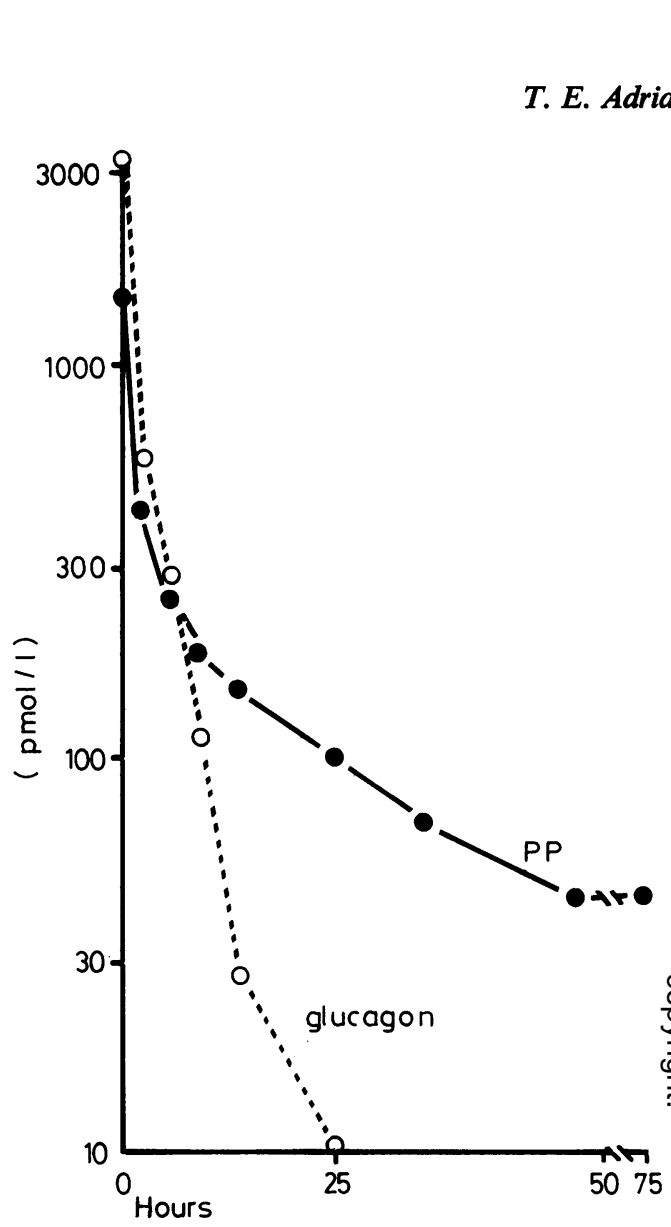

of a pancreatic tumour and may help to localise such a tumour by transhepatic portal venous catheterisation (Ingemansson et al., 1971). Plasma PP may also be a useful indicator for assessing the response to treatment, particularly of VIPomas in which PP levels are often far higher than those of VIP, which is in part because of the more rapid clearance of VIP, the half life of which is less than one minute. In contrast to the very high incidence of a raised plasma PP concentration in patients with pancreatic VIPomas (Table), VIP secreting tumours outside the pancreas, for example ganglioneuroblastomas, are associated with normal PP levels. The finding of a raised PP level in the plasma of a patient with raised VIP and watery diarrhoea thus strongly suggests that a pancreatic tumour is responsible for the syndrome.

Plasma PP levels return to normal after resection of the tumour in patients with a benign adenoma. The rate at which the level falls postoperatively is slower than would be expected from the observed half life of PP during infusion experiments (Fig. 7). This is because of the presence of high molecular weight forms of PP in the plasma of these patients (Bryant et al., 1978).

\section{PANCREATIC ADENOCARCINOMA}

Fasting plasma PP concentrations in a group of 13 patients with adenocarcinoma of the pancreas were not significantly different from those of patients with adenocarcinoma of the stomach, colon, rectum, bronchus, or breast, or from those of normal subjects of similar age (Bloom et al., 1978).

\section{CARCINOID TUMOURS}

Fasting plasma PP concentrations were raised in 10 of 20 patients with carcinoid tumours (Bloom et al., 1978). The presence of high circulating PP concentrations did not appear to be related to the site of the primary tumour, and the incidence of diarrhoea and flushing was similar in the two groups of patients. The degree of weight loss and the urinary excretion of 5HIAA was also similar in the two groups.

Tumour was examined for PP in three of the patients with raised plasma levels, and PP-like

\begin{tabular}{lccc}
\hline & $\begin{array}{l}\text { Total No } \\
\text { studied }\end{array}$ & $\begin{array}{l}\text { No fasting } \\
\text { PP raised } \\
(300 \text { pmol/l) }\end{array}$ & $\begin{array}{l}\% \\
\text { positive }\end{array}$ \\
\hline Vipoma & 49 & 31 & 63 \\
Insulinoma & 17 & 4 & 24 \\
Gastrinoma & 60 & 15 & 25 \\
PPoma & 1 & 1 & 100 \\
Glucagonoma & 14 & 7 & 50 \\
Adenocarcinoma & 16 & 0 & 0 \\
\hline
\end{tabular}

Table Plasma PP in patients with pancreatic tumours

Fig. 7 Effect of tumour resection on plasma PP and glucagon concentrations in a patient with a benign pancreatic glucagonoma. Both PP and glucagon levels fell to within the normal range postoperatively.

immunoreactivity was detectable in both primary and metastatic tissue. Only one major peak of PPlike immunoreactivity was detected by Sephadex gel chromatography in each case (Fig. 8).

\section{The future of PP research}

Although PP was only discovered a decade ago, N considerable progress has been made in establishing $N$ this peptide as a gut hormone. Much is now known N about the mechanism of PP release after a meal and $\frac{\omega}{\sigma}$ its physiological role in man, and some interesting observations on its pathophysiology have emerged. There remain some unanswered questions including $\stackrel{\Phi}{\stackrel{\oplus}{+}}$ the nature of the factor or factors from the gut which potentiate PP release after food, whether PP has 0 physiological effects other than on the gall bladder $\mathbb{D}$ and exocrine pancreas, and whether PP can be used $\frac{\rho}{\mathbb{P}}$ as a clinically useful marker for pancreatic endocrine $\frac{Q}{\sigma}$
tumours. 


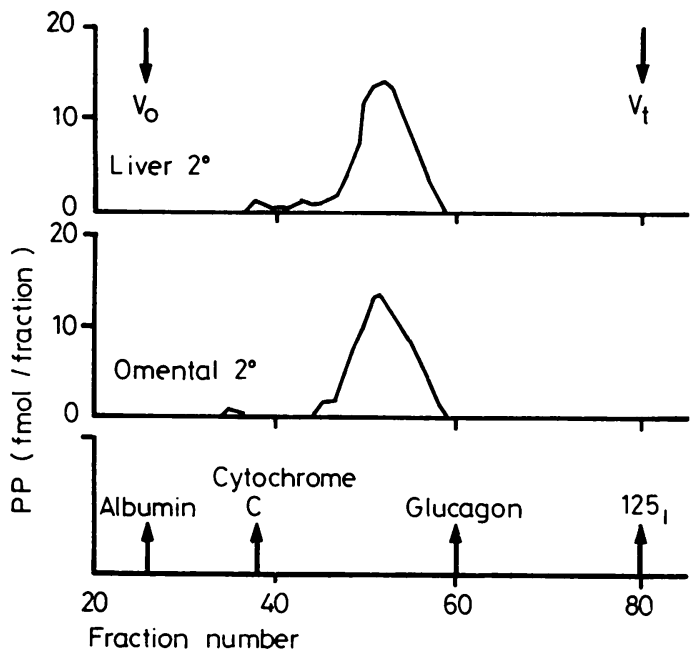

Fig. 8 Gel chromatography of PP immunoreactivity in tumour extracts from 2 metastatic carcinoid tumours. One major peak was seen eluting in the same position as pure natural human PP.

\section{References}

Adrian, T. E., Besterman, H. S., Christofides, N. D., and Bloom, S. R. (1978a). Interaction of gastrointestinal hormones and cholinergic innervation on the release of pancreatic polypeptide (Abst.). Scandinavian Journal of Gastroenterology, 13, Suppl. 49, 1.

Adrian, T. E., Besterman, H. S., Mallinson, C. N., Czaykowska, W. M., and Bloom, S. R. (1977a). Studies on the release of pancreatic polypeptide and its relationship to pancreatic exocrine function (Abst.). Journal of Endocrinology, 75, 35P-36P.

Adrian, T. E., Besterman, H. S., Mallinson, C. N., Garalotis, C., and Bloom, S. R. (1979a). Impaired pancreatic polypeptide release in chronic pancreatitis with steatorrhoea. Gut, 20, 98-101.

Adrian, T. E., Besterman, H. S., Mallinson, C. N., Greenberg, G. R., and Bloom, S. R. (1979b). Inhibition of secretin-stimulated pancreatic secretion by pancreatic polypeptide. Gut, 20, 37-40.

Adrian, T. E., Bloom, S. R., Besterman, H. S., Barnes, A. J., Cook, T. J. C., Russell, R. C. G., and Faber, R, G. (1977b). Mechanism of pancreatic polypeptide release in man. Lancet, 1, 161-163.

Adrian, T. E., Bloom, S. R., Bryant, M. G., Polak, J. M., Heitz, P., and Barnes, A. J. (1976). Distribution and release of human pancreatic polypeptide. Gut, 17, 940-944.

Adrian, T. E., Bloom, S. R., Hermansen, K., and Iversen, J. (1978b). Pancreatic polypeptide, glucagon and insulin secretion from the isolated perfused canine pancreas. Diabetologia, 14, 413-417.

Adrian, T. E., Greenberg, G. R., Besterman, H. S., and Bloom, S. R. (1978c). Pharmacokinetics of pancreatic polypeptide in man. Gut, 19, 907-909.
Adrian, T. E., Greenberg, G. R., Besterman, H. S., Christofides, N. D., and Bloom, S. R. (1978d). PP infusion in man: pharmacokinetics at 3 dose levels and effects on gastrointestinal and pancreatic hormones (Abst.). Scandinavian Journal of Gastroenterology, 13, Suppl. 49, 3.

Adrian, T. E., Greenberg, G. R., Besterman, H. S., McCloy, R. F., Chadwick, V. S., Barnes, A. J., Mallinson, C. N., Baron, J. H., Alberti, K. G. G. M., and Bloom, S. R. (1978e). PP infusion in mansummary of initial investigations. In Gut Hormones, pp. 265-267, ed. S. R. Bloom. Churchill Livingstone, Edinburgh.

Adrian, T. E., Greenberg, G. R., McCloy, R. F., Fitzpatrick, M. L., and Bloom, S. R. (1979c). How to assess the physiological role of a new peptide hormone: pancreatic polypeptide infusion in man. Journal of Endocrinology (in press).

Besterman, H. S., Bloom, S. R., Adrian, T. E., Christofides, N. D., Sarson, D. L., Mallinson, C. N., Pero, A., and Modigliani, R. (1978a). Gut hormone profile after gut resection (Abst.). Gut, 19, A972.

Besterman, H. S., Bloom, S. R., Christofides, N. D., Mallinson, C. N., Pera, A., and Modigliani, R. (1978b). Gut hormone profile in inflammatory bowel disease (Abst.). Gut, 19, A988.

Besterman, H. S., Sarson, D. L., Blackburn, A. M., Cleary, J., Pilkington, T. R. E., Gazet, J. C., and Bloom, S. R. (1978c). Gut hormone profile in morbid obesity and following jejunoileal bypass (Abst.). Gut, 19, A986.

Bloom, S. R., Adrian, T. E., Barnes, A. J., and Polak, J. M. (1979). Autoimmunity in diabetics induced by hormonal contaminants of insulin. Lancet, 1, 14-17.

Bloom, S. R., Adrian, T. E., Pera, A., Polak, J. M., Besterman, H. S., Modigliani, R., Bryant, M. G., Modlin, I. M., Barnardo, D. E., and Grahame-Smith, D. G. (1978). PP in patients with the carcinoid syndrome, pancreatic endocrine tumours and adenocarcinomas (Abst.). Gastroenterology, 74, 1012.

Bryant, M. G., Bloom, S. R., Adrian, T. E., and Mallinson, C. N. (1978). Chromatographic analysis of tumour produced hormones (Abst.). Gut, 19, A445.

Chance, R. E., Root, M. A., and Galloway, J. A. (1976). The immunogenicity of insulin preparations. Acta Endocrinologica, 83, Suppl. 205, 185-196.

Coleman, D. L. (1978). Obese and diabetes: two mutant genes causing diabetes-obesity syndromes in mice. Diabetologia, 14, 141-148.

Floyd, J. C., Fajans, S. S., and Pek, S. (1976). Regulation in healthy subjects of the secretion of human pancreatic polypeptide, a newly recognised pancreatic islet polypeptide. Transactions of the Association of American Physicians, 89, 146-158.

Floyd, J. C., Fajans, S. S., Pek, S., and Chance, R. E. (1977). A newly recognised pancreatic polypeptide; plasma levels in health and disease. Recent Progress in Hormone Research, 33, 519-570.

Greenberg, G. R., McCloy, R. F., Adrian, T. E., Baron, J. H., and Bloom, S. R. (1978a). Effect of bovine pancreatic polypeptide on gastric acid and pepsin 
output in man. Acta Hepato-Gastroenterologica, 25, 384-387.

Greenberg, G. R., McCloy, R. F., Adrian, T. E., Chadwick, V. S., Baron, J. H., and Bloom, S. R. (1978b). Inhibition of pancreas and gallbladder by pancreatic polypeptide. Lancet, 2, 1280-1282.

Greenberg, G. R., McCloy, R. F., Chadwick, V. S., Adrian, T. E., Baron, J. H., and Bloom, S. R. (1979). Effect of bovine pancreatic polypeptide on basal pancreatic and biliary outputs in man. Digestive Diseases and Sciences, 24, 11-14.

Hazelwood, R. L., Turner, S. D., Kimmel, J. R., and Pollack, H. G. (1973). Spectrum effects of a new polypeptide (Third Hormone?) isolated from the chicken pancreas. General and Comparative Endocrinology, 21, 485-497.

Heitz, P., Polak, J. M., Bloom, S. R., and Pearse, A. G. E. (1976). Identification of the $D_{1}$ cell as the source of human pancreatic polypeptide (HPP). Gut, 17, 755-758.

Ingemansson, S., Holst, J., Larsson, L., and Lunderquist, A. (1971). Localization of glucagonomas by catheterization of the pancreatic veins and with glucagon assay. Surgery, Gynecology and Obstetrics, 145, 509-516.

Kimmel, J. R., Pollock, H. G., and Hazelwood, R. L. (1968). Isolation and characterisation of chicken insulin. Endocrinology, 83, 1323-1330.

Larsson, L. I., Sundler, F., and Håkanson, R. (1976). Pancreatic polypeptide-a postulated new hormone: identification of its cellular storage site by light and electron microscopic immunocytochemistry. Diabetologia, 12, 211-226.

Lin, T. M., and Chance, R. E. (1974). Candidate hormones of the gut. VI. Bovine pancreatic polypeptide and avian pancreatic polypeptide. Gastroenterology, 67, 737-738.

Lin, T. M., and Chance, R. E. (1978). Spectrum of gastrointestinal actions of bovine PP. In Gut Hormones, pp. 242-246, ed S. R. Bloom. Churchill Livingstone, Edinburgh.

Lin, T. M., Evans, D. C., Chance, R. E., and Spray, G. F. (1977). Bovine pancreatic polypeptide: action on gastric and pancreatic secretion in dogs. American Journal of Physiology, 232, E311-E315.

Malaisse-Lagae, F., Carpentier, J. L., Patel, Y. C., Malaisse, W. J., and Orci, L. (1977). Pancreatic polypeptide: a possible role in the regulation of food intake in the mouse. Hypothesis. Experientia, 33, 915-917.

Marco, J., Hedo, J. A., and Villanueva, M. L. (1977). Inhibitory effect of somatostatin on human pancreatic polypeptide secretion. Life Sciences, 21, 789-792.

Orci, L., Baetens, D., Ravazzola, M., Stefan, Y., and Malaisse-Lagae, F. (1976). Pancreatic polypeptide and glucagon: non-random distribution in pancreatic islets. Life Sciences, 19, 1811-1815.

Polak, J. M., Bloom, S. R., Adrian, T. E., Heitz, P., Bryant, M. G., and Pearse, A. G. E. (1976). Pancreatic polypeptide in insulinomas, gastrinomas, VIPomas and glucagonomas. Lancet, 1, 328-330.

Schwartz, T. W., Grotzinger, U., Schöön, I. M., and Olbe, L. (1979). Vago-vagal stimulation of pancreatic polypeptide secretion by graded distension of the gastric fundus and antrum in man. Digestion, 19, 307-314.

Schwartz, T. W., Holst, J. J., Fahrenkrug, J., Lindkaer cे Jensen, S., Nielsen, O. V., Rehfeld, J. F., Schaffalitzky O De Muckadell, O. B., and Stadil, F. (1978). Vagal, ב cholinergic regulation of pancreatic polypeptide secretion. Journal of Clinical Investigation, 61, 781-789.

Schwartz, T. W., Stadil, F., Chance, R. E., Rehfeld, J. F., Larson, L-I., and Moon, N. (1976). Pancreaticpolypeptide response to food in duodenal-ulcer patients before and after vagotomy. Lancet, 1, 1102-1105.

Solcia, E., Pearse, A. G. E., Grube, D., Kobayashi, Bussolati, G., Creutzfeldt, W., and Gepts, W. (1973 Revised Wiesbaden classification of gut endocrine cells Rendiconti di Gastro-enterologia, 5, 13-16.

Solcia, E. et al. (1978). Lausanne 1977 classification of gastroenteropancreatic endocrine cells. In GutHormones, pp. 40-48, ed S. R. Bloom. Churchill Livingstone. Edinburgh.

Taylor, I. L., Feldman, M., Richardson, C. T., and Walsh, J. H. (1978a). Gastric and cephalic stimulation of human pancreatic polypeptide release. Gastroenterology, 75, 432-437.

Taylor, I. L., Solomon, T. E., Walsh, J. H., and Grossman, M. I. (1978b). Physiological blood levels of pancreatic polypeptide (PP) inhibit pancreatic secretion (Abst.). Gastroenterology, 74, 1102.

Taylor, I. L., Walsh, J. H., Rotter, J., and Pessaro, E., Jr. (1978c). Is pancreatic polypeptide a marker for 윽 Zollinger-Ellison syndrome? Lancet, 1 , 845-848. 